\title{
Write between the lines: Electronic outlining and the organization of text ideas
}

Citation for published version (APA):

De Smet, M., Brand-Gruwel, S., Broekkamp, H., \& Kirschner, P. A. (2012). Write between the lines: Electronic outlining and the organization of text ideas. Computers in Human Behavior, 28(6), 2107-2116.

https://doi.org/10.1016/j.chb.2012.06.015

DOI:

10.1016/j.chb.2012.06.015

Document status and date:

Published: 01/11/2012

Document Version:

Version created as part of publication process; publisher's layout; not normally made publicly available

Please check the document version of this publication:

- A submitted manuscript is the version of the article upon submission and before peer-review. There can be important differences between the submitted version and the official published version of record. People interested in the research are advised to contact the author for the final version of the publication, or visit the DOI to the publisher's website.

- The final author version and the galley proof are versions of the publication after peer review.

- The final published version features the final layout of the paper including the volume, issue and page numbers.

Link to publication

\section{General rights}

Copyright and moral rights for the publications made accessible in the public portal are retained by the authors and/or other copyright owners and it is a condition of accessing publications that users recognise and abide by the legal requirements associated with these rights.

- Users may download and print one copy of any publication from the public portal for the purpose of private study or research.

- You may not further distribute the material or use it for any profit-making activity or commercial gain

- You may freely distribute the URL identifying the publication in the public portal.

If the publication is distributed under the terms of Article 25fa of the Dutch Copyright Act, indicated by the "Taverne" license above, please follow below link for the End User Agreement:

https://www.ou.nl/taverne-agreement

Take down policy

If you believe that this document breaches copyright please contact us at:

pure-support@ou.nl

providing details and we will investigate your claim.

Downloaded from https://research.ou.nl/ on date: 26 Apr. 2023 


\title{
Write between the lines: Electronic outlining and the organization of text ideas
}

\author{
M.J.R. de Smet ${ }^{\mathrm{a}, *}$, S. Brand-Gruwel ${ }^{\mathrm{a}}$, H. Broekkamp ${ }^{\mathrm{b}, \mathrm{c}}$, P.A. Kirschner ${ }^{\mathrm{a}}$ \\ ${ }^{a}$ Open University in the Netherlands, Centre for Learning Sciences and Technologies (CELSTEC), P.O. Box 2960, 6401 DL Heerlen, The Netherlands \\ ${ }^{\mathrm{b}}$ Utrecht University, Faculty of Social and Behavioural Sciences, Heidelberglaan 1, P.O. Box 80140, 3508 TC Utrecht, The Netherlands \\ ${ }^{\mathrm{c}}$ University of Amsterdam, Faculty of Social and Behavioural Sciences (FMG), Nieuwe Prinsengracht 130, 1018 VZ Amsterdam, The Netherlands
}

\section{A R T I C L E I N F O}

\section{Article history:}

Available online $\mathrm{xxxx}$

\section{Keywords:}

Electronic outlining

Outline tool

Argumentative writing

Text organization

Student writing

Writing process

\begin{abstract}
A B S T R A C T
Writing is an important, complex skill which could be enhanced through the effective use of writing tools that are incorporated in word processors. The main objective of this study was to examine the effect of (repeated) electronic outlining on the quality of students' writing products and perceived mental effort. The study also investigated how students appropriate and appreciate the outline tool. Data were collected from 58 ninth-grade students who wrote two argumentative texts about a topic they had previously discussed during several class sessions, meaning that ideas were generated and clustered beforehand. Students' writing products were scored for Total Text Structure, Structure Presentation, and Hierarchical Elaboration of Arguments. Results reveal that first-time tool-use had no significant effect on students' writing products and perceived mental effort. However, repeated use positively affected Structure Presentation and led to decreased perceived mental effort, but no significant effect was found on Total Text Structure and Hierarchical Elaboration of Arguments. Answers to a retrospective questionnaire showed that students quickly appropriated the tool with tool appreciation increasing with repeated use. This study suggests that in order to profit from electronic outlining, it is important to practice using the outline tool and to use it for complex tasks, requiring idea generation and organization.
\end{abstract}

(ㄷ) 2012 Elsevier Ltd. All rights reserved.

\section{Introduction}

\subsection{Writing as a complex skill}

Writing is an important skill for both the educational and the professional career in today's knowledge-driven society (Duijnhouwer, 2010; U.S. Department of Education, 2003). As a result, education devotes much attention to the development of students' writing ability. However, writing a text is a complex and demanding task entailing hard work (Flower \& Hayes, 1980; Kellogg, 1994; Schilperoord, 1996; van Weijen, 2007). Writing is a cognitive activity consisting of a constant and recursive process in which the writer engages in the alternating processes of planning, translating, and reviewing. It is an interplay between organization and style; about what should be in the text and how it should be presented. Flower and Hayes describe writing as "the act of dealing with an excessive number of simultaneous demands and constraints" (p. 33).

Writing an elaborated text not only makes demands on the writers' language system but also on their cognitive systems for memory and thinking because mental products (e.g., what one is

\footnotetext{
* Corresponding author. Tel.: +31 45576 2909; fax: +31 455762800.

E-mail addresses: Milou.desmet@ou.nl (M.J.R. de Smet), Saskia.Brand-Gruwel@ ou.nl (S. Brand-Gruwel), H.Broekkamp@uva.nl (H. Broekkamp), Paul.Kirschner@ ou.nl (P.A. Kirschner).
}

planning to include in the text being written, how one plans to structure the text) need to be kept in working memory (Kellogg, 2008; Kellogg \& Whiteford, 2009). This working memory however, has only a limited capacity for information processing and storage (Kellogg, 1996). The alternation of the cognitive processes of planning, translating, and reviewing puts a heavy load on a writers' attentional capacity (Kellogg, 1994). Writers therefore often experience cognitive overload while composing a text (Flower \& Hayes, 1980). Cognitive load refers to the amount of mental effort expended and is a function of the number of novel elements that need to be kept in working memory and the degree of interaction between those elements (Kirschner, 2002). When the amount of effort that needs to be expended exceeds the capacity of working memory, this may cause cognitive overload. This phenomenon is particularly a problem for writers who are learning to write. These novice writers must simultaneously perform a writing task and a learning-to-write task (Braaksma, 2002). Therefore, students (who, generally, are novices when it comes to writing) often have problems writing an elaborated and well-structured text. They usually focus more on lower level goals such as word choice or grammatical issues and less on higher level goals such as text structuring (Faigley \& Witte, 1981; Flower \& Hayes, 1981; Kozma, 1991).

Students' writing skills could be enhanced if the expended mental effort during writing is decreased. The problem of cognitive (over)load can be suppressed if students learn to effectively use 
writing strategies that help them monitoring and directing their writing process. The two most well-defined strategies for writing are a planning strategy and a revising strategy (Kieft, 2006; Kieft, Rijlaarsdam, Galbraith, \& Van den Berg, 2007). These strategies allow the separate management of the different subtasks of writing and consequently reduce the number of simultaneous constraints. This helps managing the complexity of writing and as a consequence enhances students' writing performance (Coirier, Andriessen, \& Chanquoy, 1999; Kellogg, 1988; Piolat \& Roussey, 1996). This study focuses on the effect of using a planning strategy for writing.

\subsection{Outlining as a planning strategy}

Planning strategies have been found to positively influence students' writing performance by means of content-exploration and text-planning (Torrance, Thomas, \& Robinson, 2000). Probably the most recommended planning strategy for novice writers is outlining (Galbraith, Ford, Walker, \& Ford, 2005; Hayes, 2006). Following Walvoord et al. (1995) outlining is the process of producing "a written vertical list of ideas or information in the sequence that the writer intends for the final piece of writing" (p. 400). An outline is a text plan that is made by a writer before fully elaborating a text. This type of planning has, broadly, two functions. First, it can facilitate idea generation and retrieval and second, it allows writers to organize and elaborate their ideas into structured arrangements (Englert, Zhao, Dunsmore, Collings, \& Wolbers, 2007; Galbraith et al., 2005). It helps a writer to think - at an early stage in the writing process - about the organization and structure of a desired product and/or the steps that need to be followed (Hayes \& Nash, 1996). Making an outline can improve text structure because it shifts the writers' focus from the lower level of text-bound considerations to a higher, more structural level (Kozma, 1991).

The form and functions of outlines may vary widely depending on the type of writer and/or text to be written (Walvoord et al., 1995). An outline may consist of nothing more than a simple list

\section{Argumentative text}

\section{Introduction}

A. Anecdote

B. Formulation of the problem

C. Presenting point of view

II. Body

A. Arguments

1. Argument 1

a. Subargument

b. Sub argument

2. Argument 2

a. Sub argument

3. Argument 3

a. Subargument

B. Counterarguments

1. Counterargument 1

$$
\text { a. Refutation }
$$

2. Counterargument 2

a. Refutation

b. Refutation

III. Conclusion
A. Summarize most important arguments
B. Encourage reader to take action
C. Powerful clincher

Fig. 1. Example of a hierarchical elaborated outline. of ideas, or it may involve an elaborated, well ordered hierarchy of ideas and relationships. Such a hierarchical outline (see Fig. 1) is typically a support for writers to organize their thoughts.

Outlines have, traditionally, been produced with pen and paper. However, writers can nowadays profit from using word processors and the growing menu of embedded tools that support writing by facilitating the writing process (Deacon, Jaftha, \& Horwitz, 2004; Kozma, 1991; Price, 1997). An example of such a tool is the outline tool which enables writers to easily create outlines with which they can organize and subsequently elaborate their text ideas. The advantage of an electronic outline tool is its increased flexibility by enabling writers to (1) easily adapt their outlines, (2) fold and unfold parts of the text, and (3) present the outline and the full text simultaneously on the computer screen (cf. Erkens, Jaspers, Prangsma, \& Kanselaar, 2005; Price, 1997). Although available to almost all writers, such tools remain relatively unknown and, thus, unused. Modern word processors are over-dimensioned with many more functions than a user knows of or typically uses. According to the Technology Acceptance Model (TAM), perceived usefulness and perceived ease-of-use are the two most significant determinants of users' attitudes, intentions and actual technology adoption behavior (Davis, 1986, 1989; Venkatesh \& Davis, 2000). The potential to use and appreciate a technology lies, thus, in the benefits it offers to its users. But first, the user has to know that it exists. In other words, students' usage, as well as their attitude towards using a tool like the outline tool first depends on using it (i.e., becoming aware of its existence), after which usage might increase with the experience of increased tool benefits. It is important to examine the potential of electronic outlining since many tools - though designed and developed with the best intentions - fail because the intended users refuse to use them.

Not much is known about the uses and benefits of electronic outlining nor about how students appreciate working with such an electronic outline tool. However, a substantial number of studies have investigated the effects of traditional outlining on writing performance (see Galbraith et al., 2005; Hayes, 2006; Kozma, 1991; Price, 1997). The underlying principles of outlining (i.e. planning and organizing text ideas) that are characteristic for traditional outlining also apply for electronic outlining. These studies and their findings are therefore also relevant within the scope of electronic outlining.

\subsection{Effects of outlining}

Most studies show that using an outline strategy positively impacts writing performance and leads to increased text quality (Erkens, Kanselaar, Prangsma, \& Jaspers, 2002; Galbraith et al., 2005; Glynn, Britton, Muth, \& Dogan, 1982; Kellogg, 1987, 1988, 1990; Kozma, 1991). In addition, outlining may decrease mental effort expended during writing. By planning in advance, writers may free up cognitive resources for translating and reviewing at a later stage. Kellogg (1988) examined the mental effort expended during each of the sub-processes of writing by using directed retrospection and secondary-task reaction times. Results suggest that outlining alleviated attentional overload by enabling writers to focus their attention on one single sub-process a time. Kellogg's study shows that freeing up cognitive resources for translating is important to enhance writing.

Galbraith et al. (2005) concluded with respect to outlining that "although good evidence exists that it has beneficial effects, much less is known about how it achieves these effects" (p. 113). To understand the mechanisms by which outlining exerts influence on writing, the common distinction between the three main components of the writing process - planning, translating, and reviewing - can be used as a starting point (see Flower \& Hayes, 1981). Plainly, outlining as a planning strategy will directly influence 
the planning process of writing. However, because planning, translating, and revising interact with one another, outlining may also influence the translating and reviewing process in an indirect way. Walvoord et al. (1995) demonstrated that college students use outlines as a bridge between planning and translating. Outlines helped them to overcome the fundamental problem of linearization in writing; that is developing a sequential text structure out of mental text ideas that do not have a sequential order by nature (McCutchen, 1987). Linearization is especially a problem for literary genres such as argumentation, where writers cannot structure their text through simple approaches such as causal, chronological, or spatial organization. Instead, to satisfy complex argumentative constraints, students must transpose their often multidimensional mental structures into a linguistic sequence of sentences and an organized text (Coirier, Favart, \& Chanquoy, 2002; Coirier et al., 1999; Erkens et al., 2005; McCutchen, 1987). It is at this point in the writing process that outlining might help bridging between initial mental associations and their translation into a coherent and logically structured text.

Nevertheless, outlining may not be effective for all situations. For instance, for writing routine documents in which the structure is repetitious and self-evident, outlining may be rather pointless. In such situations, the writer would rather start immediately elaborating the text without first drawing an outline (Kellogg, 1988). Similarly, a writer who has only very vague ideas about the text to be produced may prefer drafting or brainstorming over producing an outline (Kellogg, 1988). Elbow (1998) indicated that outlining is relatively useless when a writer does not yet know much of what he or she wants to write. He stresses that "outlining is most effective when you already know many of the ideas or incidents or images you want to use in your writing and you are trying to clarify and organize them" (p. 39-40). This suggests that students would profit most from outlining when ideas have been generated in an earlier stage and when it is used to organize these text ideas in a sequential text structure. Freeing up cognitive resources (i.e. through generating text ideas in advance) would alleviate attentional overload and help students to focus on outlining and sequentially organizing their text ideas (cf. Kellogg, 1988).

In a society in which everyone writes their texts in a computer based environment, it is highly relevant to examine what the effect is of electronic outlining. Instead of drawing an outline with pen and paper, writers might profit from the embedded electronic outline function in their word processors. Electronic outlining might facilitate writing because of its built-in flexibility that provides writers to easily create and adapt their outlines; to insert text parts anywhere in the outline and to move parts from one place to another or from one level of subordination to another (cf. Kozma, 1991). However, not much is known about the effect of electronic outlining and the organization of previously generated text ideas. It remains to be seen what the effects are of this specific context and these specific instructions on students' writing performance.

\subsection{This study}

The present study investigates the effect of electronic outlining on students' writing performance (i.e. Total Text Structure, Structure Presentation, and Hierarchical Elaboration of Arguments) and perceived mental effort encountered while writing. The participants had already generated text ideas and clustered these ideas into mental structures during several previous class discussions. Outlining is, thus, used here as a tool to help organize generated text ideas into a linear and sequential written structure. Based on prior studies (e.g. Kellogg, 1988) it is expected (H1) that electronic outlining contributes to the quality of students' writing products because it enables them to better organize the generated text ideas and sentences according to a linear structure. Outlining would directly help them solve the linearization problem and focus on higher level goals such as text structuring.

In addition, the effect of repeatedly using an outline tool is examined. It is expected $(\mathrm{H} 2)$ that repeated tool-use will lead to further improvement of text quality because of students' tool appropriation and use-optimization. Practicing with the tool might reduce the demands of the tool appropriation process to free up working memory space for the writing process.

In this study, the focus is not only on the quality of the final writing products but also on the process of writing and the mental effort that comes with it. Bridging between product and process enables a more detailed picture of the influence of electronic outlining on students' writing performance. Based on Kellogg's research on writing and cognitive load, it is hypothesized (H3) that outlining as a planning strategy will free up cognitive resources in a later phase of the writing process. Students using the outline strategy are, therefore, likely to perceive less mental effort while performing their writing task than students who do not use the outline strategy. Moreover, students' mental effort will continue to decrease with repeated tool-use. Tool practice might help students to gradually automate the process of electronic outlining and help them gain control over their cognitive processes (Kellogg \& Whiteford, 2009; Shaffer, Doube, \& Tuovinen, 2003).

Finally, this study seeks to determine whether students appropriate and appreciate working with the outline tool. Based on the Technology Acceptance Model (Davis, 1986, 1989; Venkatesh \& Davis, 2000) it is expected (H4) that students' positive attitude towards the outline tool increases along with the experience of increased tool benefits.

This leads to the following research questions:

1. What is the effect of electronic outlining on students' writing performance when used for idea organization?

2. What is the effect of repeated electronic outlining?

3. What is the effect of electronic outlining on perceived mental effort?

4. How do students appropriate and appreciate electronic outlining?

\section{Method}

\subsection{Participants}

In this experiment 58 ninth-grade students from a Dutch preuniversity secondary school participated. The group consisted of 22 male and 36 female participants between the ages of 14 and 16 years $(M=14.7 ; S D=0.70)$. Students were randomly assigned to one of two experimental conditions in which they carried out two similar writing tasks. Participation in the experiment was compulsory as the tasks were part of the regular curriculum.

\subsection{Design}

This study compared two experimental conditions in a combined within-subjects and between-subjects design. This combined design enabled determination of the effects of single and repeated use of electronic outlining on students' writing performance. In addition, it controls for unintended effects that could interfere with the effects of electronic outlining and their interpretation such as initial differences in competence between the participants in the two experimental conditions and possible learning effects of repeatedly performing a writing task. According to the study's design (Fig. 2), students were or were not instructed to make an electronic outline before elaborating their full text. 


\begin{tabular}{|l|l|l|}
\hline & Task1 & Task2 \\
\hline O-O+ condition $(n=26)$ & No outline & Outline \\
\hline O+O+ condition $(n=32)$ & Outline & Outline \\
\hline
\end{tabular}

Fig. 2. Design of the study $\left(\mathrm{O}^{+}=\right.$with outline tool; $\mathrm{O}_{-}=$without outline tool $)$.

\subsection{Context}

In the 5 weeks preceding the writing tasks, students engaged in a project on politics. The first part of the project lasted 3 weeks and focused on historical and economic issues, while the final 2 weeks focused on current politics including class discussions on current social issues. In this second part of the project, students formed their own political system with invented parties, an election council, a press bureau, a social-economic council, a financial bureau, lobbying groups, and a queen. In their varying roles, students prepared for and carried out different activities which were focused on four major events: (a) a press conference in which party representatives presented their electoral program (i.e., party platform) about a number of specific social issues to the general public (i.e., the other students), and in which the monarch gave a state of the nation address; (b) a debate in which party representatives, in interaction with the audience (i.e., the other students), discussed the social issues that were put on the agenda by the election council; (c) an election market in which parties and lobbying groups presented and explained their programs by means of flyers and posters; and (d) the final elections.

The issues - determined by the election council - were announced prior to the debate so that party representatives and the audience could generate and prepare arguments and counterarguments for and against their point of view. During the debate, students defended their own point of view by putting forward and supporting their arguments on the different social issues. Moreover, they learned to refute counter-arguments from the opposing parties. These class activities are considered to reflect the required characteristics of argumentation that students must exhibit to develop an elaborated argumentative schema. The writing tasks formed the conclusion of the 5-week school project on politics.

\subsection{Materials}

\subsubsection{Writing tasks}

Students in both conditions carried out two argumentative writing tasks, each of 400-600 words long. An argumentative text was chosen because writers cannot structure this genre through simple or self-evident structures such as causality, chronology, or spatial organization (Coirier et al., 1999). Electronic outlining might help students here to transpose their arguments and mental associations into a linear argumentative structure.

Students were required to choose two social issues (i.e., one for each task) from a list of 20 predefined issues which were debated in class during the project period. This specific context created a writing condition that de-emphasized the generation and clustering of ideas (i.e., these task demands had, in part, taken place at an earlier stage of the project) and emphasized the organization of these ideas (i.e., the structuring of earlier generated ideas in an argumentative text). As Elbow (1998) suggested, outlining may be most effective when writers already know what ideas should be in the text. Outlining would, in this case, especially help writers to linearize previously generated ideas.
Students' freedom of choice for the texts' topics was considered to be an important component of the writing task because it would motivate students to produce an effectively persuasive text containing understandable and acceptable arguments (cf. Glynn et al., 1982). The writing tasks were given by means of a written instruction which was equivalent for the two conditions (i.e., with and without outline tool) except for the specific requirement to use the outline tool. The instruction informed students about the required product characteristics, procedure and available time. In addition, the instruction included a short prompt about the required organization of the argumentative text genre (i.e., defend a standpoint with arguments and address counter arguments). Results from a pilot study showed that students might need these prompts to activate their prior knowledge on argumentative writing (cf. Kozma, 1991).

\subsubsection{Writing procedure}

Both writing tasks were conducted consecutively on the same day. For each writing task, students had 45 min with a 15 -min break between them. Students carried out both tasks individually in the school's computer room with Microsoft Office Word (MSWord) $2003^{\circledR}$ which was installed on their computers. This word processor included a tool for outlining.

Students in the $\mathrm{O}-\mathrm{O}+$ condition were instructed that they had 45 min to write an argumentative text (Task 1 ) as they had learned to do in class. As part of their regular curriculum, students learned how to write an argumentative text and how to use planning strategies to compose their texts. However no explicit instructions were given on using planning strategies. For tasks that required using the outline tool, students were explicitly instructed to spend the first 10 min on electronic outlining and then elaborate the full text in the remaining $35 \mathrm{~min}$. An explicit subdivision of the writing task was made because it was assumed that using the outline tool was new for students. Without procedural facilitation, students might experience difficulties managing their writing time (cf. Bereiter \& Scardamalia, 1987).

\subsubsection{Tool training}

Prior to the first writing task requiring the use of the outline tool, a 10-min training was given to explain the tool and its working. Students in the $\mathrm{O}+\mathrm{O}+$ condition received the training prior to their first writing task, while students in the $\mathrm{O}-\mathrm{O}+$ condition received the training only prior to their second writing task. The training was given by the first author and supported by a digital projector. The outline tool was demonstrated by working out an abstract example in which the structure of a house was composed. While demonstrating the tool, the researcher pointed out the different buttons available on the toolbar and how they could be used. Care was taken to limit the training to technical tool-use and not on how the tool could be used to structure or write an argumentative text. The demonstration was followed by a 5-min technical practice session in which students individually used the outline function to elaborate the hierarchical construction of their own homes.

The tool used in this study was the outline function embedded in the 'view' menu in MSWord $2003{ }^{\circledR}$ (see Fig. 3). The advantage of this specific outline tool is that it is directly available for everyone in the standard settings of a widely used word processor. Moreover, students are familiar with working on writing tasks in MSWord, so they only needed specific instruction on the outline tool itself and not on the writing environment in general.

\subsubsection{Questionnaire concerning control variables}

Students completed a general self-report questionnaire to provide information on their pre-test skills, prior knowledge and writing styles (see De Smet, Broekkamp, Brand-Gruwel, \& Kirschner, 


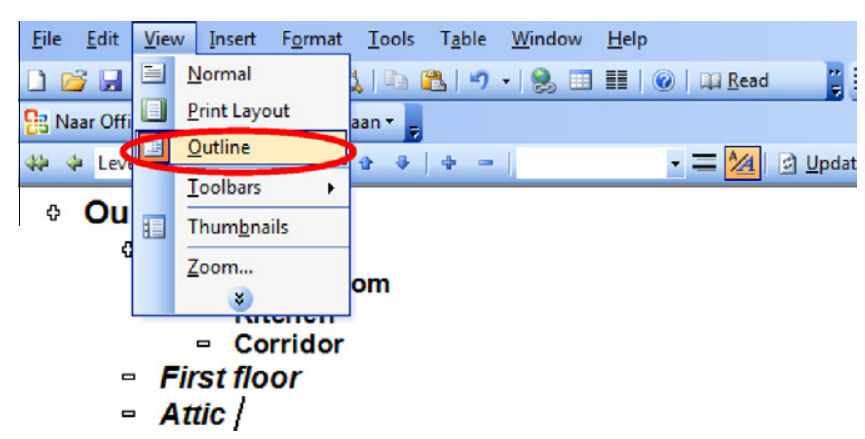

Fig. 3. Screenshot of the outline tool within Microsoft Office Word $2003^{\infty}$.

2011). The questionnaire consisted of three components which inquired about (1) computer activities, (2) self-efficacy on the argumentative text genre and, (3) usual organization of the writing process. Results from this questionnaire serve as control variables.

Questions on computer activities were partly based on the questionnaire used by Leijten (2007). Students indicated how long they have worked and how often they usually work with a personal computer and a word processor. Moreover, they indicated whether they had previously used any of 12 word processor writing functions (e.g., generating a table of contents, using headings, using the outline function).

Questions on students' self-efficacy on the argumentative text genre were based on an existing self-efficacy test for argumentative writing (Braaksma, Rijlaarsdam, \& Van den Bergh, 2009). Students indicated on a 5-point Likert scale (instead of the original 100point scale used by Braaksma et al.), for example, the extent to which they agree that they "can support [their] standpoint with strong arguments" or "take standpoints of an opponent in consideration" ( $1=$ agree; $5=$ disagree). The scale consisted of 13 items and the reliability coefficient in our study was $\alpha=.87$ which is considered to be very good (DeVellis, 1991).

Questions on students' usual organization of the writing process were based on a questionnaire developed by Kieft (2006). Using a 5-point Likert scale, students indicated the degree to which they usually engage in planning (six items, $\alpha=.71$ ) and revising activities (six items, $\alpha=.77$ ). These levels of reliability are considered to be good (DeVellis, 1991). An example of a planning question is: "When I'm going to write a text, I just jot down a few words and then I work my notes into an essay." An example of a revision question is "I usually rewrite and revise my text at least once" ( 1 = agree; 5 = disagree).

\subsubsection{Retrospective questionnaire on perceived mental effort}

To measure perceived mental effort, a retrospective questionnaire was developed in which students reported on their perceived mental effort while performing the argumentative writing tasks. Students indicated on a 5-point Likert scale how much mental effort each writing task had cost them ( 1 = very little effort; 5 = very much effort). This scale is based upon the widely used 9-point subjective cognitive load scale developed by Paas (1992). Measuring mental effort by means of a rating scale was based on Gopher and Braune's (1984) findings that people are able to introspect on their cognitive processes and have no problem rating the experienced mental effort on a numerical scale.

\subsubsection{Retrospective questionnaire on tool use and appreciation}

To measure students' experiences with the outline tool, a retrospective questionnaire was developed in which students reported on their appropriation (two items) and appreciation (two items) of the outline tool.
For tool appropriation, students indicated on a 5-point Likert scale the degree to which they appropriated the tool. The two appropriation questions were: "Did you immediately understand how to use the outline tool?" and "Did you understand how to use the tool for the argumentative writing task?" ( 1 = I completely understood it; 5 = I did not understand it at all).

Questions focusing on tool appreciation were dichotomous (yes/no). The two appreciation questions were: "Would you use the outline tool again in subsequent writing tasks?" and "Would you recommend the outline tool to a peer?"

\subsection{Data analysis}

\subsubsection{Coding procedures}

To assess text quality, the protocol by Erkens et al. (2002) for assessing argumentative text-quality, was adapted and used. The protocol distinguished the degree to which students were able to (1) correctly and completely establish a text structure (i.e. make a distinction between title, introduction, text body, and conclusion and elaborate the different characteristics of each part), (2) clearly present this structure (i.e. differentiate paragraphs, correctly use connectives and anaphora) and (3) produce complex and elaborated argumentation. A high score on these three characteristics would, thus, indicate a well-structured and elaborated argumentative text.

Credit for Total Text Structure was given when students differentiated between title, introduction, text body and conclusion. Moreover, they needed to elaborate the different characteristics of each text part. Students received a maximum score of 1 for a title (present $=1$, absent $=0$ ). A scoring rubric was used in which the presence (1) or absence (0) of different text characteristics were scored. For introduction, students could obtain a maximum score of six points, depending on the presence or absence of the introduction as such. Other elements that were evaluated and scored are 'Does the introduction attract the reader?', 'Is the topic made explicit?', 'Is the problem defined', 'Are the different positions introduced?' and 'Is the writer's own position stated?'

For the text body, students could obtain a maximum score of five points. Analysis focused here on the presence or absence of the body as such, of arguments supporting the writer's position, of examples supporting the arguments, of counterarguments, and of refutation of counterarguments.

Finally, students could obtain a maximum score of four points for their conclusion depending on the presence or absence of the conclusion as such. Furthermore, students could obtain points for summarizing the main arguments, encouraging the reader to take action and using a powerful clincher.

The maximum total score for Total Text Structure was 16 points.

Credit for Structure Presentation was given when students established an explicit presentation of the argumentative structure by correctly and sufficiently distinguishing paragraphs; a correct and sufficient use of linguistic organizers such as connectives and anaphora (cf. Chanquoy, 1996). In argumentation, employing proper connections between words and sentences can be crucial for understanding (Coirier et al., 1999). Additionally, credit for Structure Presentation was given when students showed that they had taken the reader into account (i.e., presenting to the reader and using the proper level of text formality/using the appropriate tone of voice). Finally, students received credit for showing their enthusiasm and commitment to the topic. The maximum score for Structure Presentation was 14.

The third and last variable concerning text quality was Hierarchical Elaboration of Arguments which focused on the students' ability to produce a complex and elaborated argumentation. For each (elaborated) main argument, students could obtain 0,1 or 
2 points $(0=\mathrm{a}$ main argument is presented without any elaboration, 1 = a main argument is elaborated with at least one sub argument, and 2 = main arguments are elaborated with at least one sub-sub argument). In other words, the further the argument was hierarchically elaborated and underpinned, the higher the score. For example: Smoking should be forbidden in playgrounds (position) because it has a bad influence on children (main argument $=0$ points) since it damages their health (sub argument $=1$ point) because it causes pulmonary complaints and headaches (sub sub argument $=2$ points). Finally, an average hierarchical elaboration score is calculated for each student on their total argumentative elaboration.

For both content and structure, the aforementioned characteristics of Total Text Structure, Structure Presentation, and Hierarchical Elaboration of Arguments are seen as important components of an elaborated argumentative text.

Regarding the reliability of this assessment protocol, de Smet et al. (2011) reported an interrater reliability of $\rho=.84$ for Total Text Structure and $\rho=.87$ for Structure Presentation. Regarding the reliability of Hierarchical Elaboration of Arguments, 10 random argumentative texts were rated by two researchers. Pearson correlation between the scores of the two raters in this study was .79 $(p=.006)$.

\subsubsection{Statistic techniques}

To examine the hypotheses on the effects of single and repeated use of electronic outlining on writing performance, the main dependent variables (i.e., Total Text Structure, Structure Presentation, Hierarchical Elaboration of Arguments, perceived mental effort, and tool appropriation) were tested with univariate analyses of variance (ANOVAs) for between-subjects comparisons. Moreover, the sub variables title, introduction, body and conclusion in Total Text Structure were analyzed with multiple analyses of variance (MANOVAs).

For the within-subjects comparisons, Paired Samples $t$-tests (one-way; $p<.05$ ) were used. Tool appreciation was measured by means of a $\mathrm{Chi}^{2}$ test (one-way; $p<.05$ ). Control variables were analyzed with independent $t$-tests (two-way; $p<.05$ ).

\section{Results}

Before presenting the results related to the central research questions, the general findings from the control variables are reported. Table 1 shows the means and standard deviations of the control variables and the results of the $t$-tests comparing the two conditions.

There were no significant differences between the conditions that might affect the dependent variables and the outcomes of the experiment. Both groups can, thus, be assumed to be equivalent concerning the examined control variables.

All respondents (100\%) knew how to use the basic tools in their word processors to copy and paste text and they all knew how to underline their text or use bold or italics. Moreover, most students knew how to use the tool for bullet points and numbering (98.2\%), search for specific text (94.5\%) and use the spelling checker
(94.5\%). In contrast, only 3.6\% of the students reported having ever worked with the outline tool.

\subsection{Effect of using the outline tool on students' first writing tasks}

Students' writing products were analyzed to answer the first two research questions concerning the effect of (1) electronic outlining on student's writing performance and (2) repeated use of the outline tool. Table 2 provides an overview of the means and standard deviations of the first and second writing task for both conditions.

The first research question dealt with the effect of using an electronic outline tool for organizing text ideas on student's writing products. To answer this question, students' first writing tasks were analyzed and compared. The $\mathrm{O}-\mathrm{O}+$ condition carried out the first writing task without the outline tool while the $\mathrm{O}+\mathrm{O}+$ condition used the tool to organize and write their text.

Results of the MANOVA showed a marginal effect for outlining $\left.F(1,53)=2.52, p=.052, \eta^{2}=.160\right)$ for the sub variables title, introduction, body and conclusion. Further exploration through univariate analysis of variance revealed no statistical differences for the main variable Total Text Structure. Students from both conditions performed equally regarding the elaboration of the text's structure. Contrary to the hypothesis, results showed that students not using the outline tool during the first writing task performed significantly better on the sub variable text body in which their arguments are elaborated $\left(F(1,56)=4.50, M S E=4.12, p=.04, \eta^{2}=.74\right)$. In contrast, students in the outline condition performed significantly better on the sub variable conclusion in which the main arguments are summarized and the reader is explicitly persuaded $\left(F(1,56)=4.09, M S E=4.39, p<.05, \eta^{2}=.07\right)$.

No significant differences were found on the first writing task regarding Structure Presentation. Similarly, no significant differences were found with respect to students' Hierarchical Elaboration of Arguments. Using the outline tool for the first time did here not significantly affect students' Structure Presentation or Hierarchical Elaboration of Arguments.

\subsection{Effect of repeated use of the outline tool}

The second research question examined whether and how text quality is affected when repeatedly using the outline tool. Tool practice might enhance effective use of the outline tool and thus improve writing performance. To answer this research question, task performance on the first and the second writing task are analyzed and compared for both conditions.

For the condition using the outline tool only once, no statistical differences were found across writing tasks for the main variable Total Text Structure. Electronic outlining neither enhanced nor worsened writing performance. However, contrary to the hypothesis, performance decreased significantly on the second writing task on the sub variable introduction $(t(25)=1.80 ; p=.04)$.

For the condition using the tool during both tasks, no significant differences were found between the first and second writing task concerning Total Text Structure. Moreover, no significant differ-

Table 1

Means, standard deviations and $T$-test results of the control variables.

\begin{tabular}{|c|c|c|c|c|c|c|c|}
\hline & \multicolumn{2}{|c|}{$\mathrm{O}-\mathrm{O}+(\mathrm{N}=26)$} & \multicolumn{2}{|c|}{$\mathrm{O}+\mathrm{O}+(N=32)$} & \multirow[t]{2}{*}{$d f$} & \multirow[t]{2}{*}{$t$} & \multirow[t]{2}{*}{$p$} \\
\hline & $M$ & $S D$ & $M$ & $S D$ & & & \\
\hline Knowledge of available writing tools $(\max =12)$ & 10.09 & 1.54 & 10.06 & 1.61 & 51 & 0.06 & .95 \\
\hline Knowledge of argumentative writing ( $\max =65)$ & 54.11 & 6.83 & 52.72 & 6.92 & 45 & 0.67 & .51 \\
\hline Usual writing strategies: planning $(\max =30)$ & 17.10 & 4.76 & 17.29 & 3.89 & 46 & -0.15 & .88 \\
\hline Usual writing strategies: revision $(\max =30)$ & 22.91 & 4.66 & 22.39 & 4.27 & 48 & 0.41 & .69 \\
\hline
\end{tabular}


Table 2

Means and standard deviation of text quality on Tasks 1 and 2.

\begin{tabular}{|c|c|c|c|c|c|c|c|c|}
\hline & \multicolumn{4}{|c|}{ Task 1} & \multicolumn{4}{|c|}{ Task 2} \\
\hline & \multicolumn{2}{|c|}{$\mathrm{O}-\mathrm{O}+(\mathrm{N}=26)$} & \multicolumn{2}{|c|}{$\mathrm{O}+\mathrm{O}+(N=32)$} & \multicolumn{2}{|c|}{$\mathrm{O}-\mathrm{O}+(N=26)$} & \multicolumn{2}{|c|}{$\mathrm{O}+\mathrm{O}+(N=32)$} \\
\hline & $M$ & $S D$ & $M$ & $S D$ & $M$ & $S D$ & $M$ & $S D$ \\
\hline Total text structure & 9.85 & 2.85 & 9.72 & 2.25 & 9.58 & 3.00 & 9.78 & 2.67 \\
\hline Title & 0.96 & 0.20 & 0.97 & 0.18 & 1.00 & 0.00 & 0.97 & 0.18 \\
\hline Introduction & 3.38 & 1.90 & 3.16 & 1.08 & 2.85 & 1.85 & 3.03 & 1.40 \\
\hline Body & 4.19 & 1.02 & 3.66 & 0.90 & 4.27 & 0.96 & 3.88 & 0.98 \\
\hline Conclusion & 1.38 & 0.90 & 1.94 & 1.13 & 1.46 & 1.17 & 1.84 & 1.19 \\
\hline Structure Presentation & 9.00 & 2.30 & 8.63 & 1.58 & 8.81 & 2.58 & 9.06 & 2.03 \\
\hline Hierarchical Elaboration of Arguments & 0.99 & 0.46 & 1.03 & 0.39 & 1.03 & 0.39 & 1.11 & 0.29 \\
\hline
\end{tabular}

ences were found on the four sub variables. Practice with the outline tool did not lead to increased structure elaboration.

Results of the MANOVA neither showed statistical differences for Total Text Structure on the second writing task between conditions. Practice in using the outline tool did not lead to enhanced text structure as compared to using the outline tool for the first time.

Concerning the Structure Presentation no significant differences were found between both writing tasks for students using the outline tool only once. However, analysis revealed a marginal improvement for students using the outline tool during both tasks $(t(31)=-1.04 ; p=.08)$. These students showed a tendency towards improving their Structure Presentation across both writing tasks.

For the variable Structure Presentation on the second writing task, no significant differences were found between conditions. Increased performance was found for Structure Presentation only when students repeatedly used the outline tool. These results suggest that tool practice is important in order to profit from it.

With respect to the variable Hierarchical Elaboration of Arguments, no significant differences were found both within or between conditions. Using the outline tool here did not affect students' elaboration of complex argumentation.

\subsection{Effects of the outline tool on students' perceived mental effort}

The third research question dealt with the effect of electronic outlining on perceived mental effort during the writing tasks. As discussed, using the outline tool may free up cognitive resources during the writing task since it encourages students to plan in advance. Using the outline tool might help students to control attentional allocation by focusing attention on one single sub-process of writing a time. For each writing task, students indicated on a 5-point Likert scale how much mental effort they experienced while performing the writing task (see Table 3 ).

No significant differences were found between conditions on the first writing task. During this first tool-use, students did not perceive significantly less mental effort than students not using the outline tool.

Analyses from the second writing task reveal that students in the $\mathrm{O}-\mathrm{O}+$ condition did not perceive a significant difference in mental effort across both writing tasks. A first experience with

Table 3

Means and standard deviations of perceived mental effort.

\begin{tabular}{|c|c|c|c|c|c|c|c|c|}
\hline & \multicolumn{4}{|c|}{ Task 1} & \multicolumn{4}{|c|}{ Task 2} \\
\hline & \multicolumn{2}{|c|}{$\begin{array}{l}\mathrm{O}-\mathrm{O}+ \\
(N=26)\end{array}$} & \multicolumn{2}{|c|}{$\begin{array}{l}\mathrm{O}+\mathrm{O}+ \\
(N=32)\end{array}$} & \multicolumn{2}{|c|}{$\begin{array}{l}\mathrm{O}-\mathrm{O}+ \\
(N=26)\end{array}$} & \multicolumn{2}{|c|}{$\begin{array}{l}\mathrm{O}+\mathrm{O}+ \\
(N=32)\end{array}$} \\
\hline & $M$ & $S D$ & $M$ & $S D$ & $M$ & $S D$ & $M$ & $S D$ \\
\hline $\begin{array}{l}\text { Mental effort } \\
\quad(\max =5)\end{array}$ & 2.83 & 1.19 & 2.71 & 1.04 & 2.87 & 1.22 & 2.39 & 1.09 \\
\hline
\end{tabular}

the outline tool did not significantly decrease perceived mental effort. However, the effects of repeated tool-use on mental effort are positive. Students from the $\mathrm{O}+\mathrm{O}+$ condition reported a significant decrease in perceived mental effort during their second writing task as compared to the first $(t(30)=1.77 ; p=.04)$, suggesting beneficial effects on perceived mental effort as a result of tool practice.

\subsection{Tool appropriation and appreciation}

The last research question focused on whether and to what extent students appropriate the outline tool and how they appreciate working with it. This question is examined through means of students' self-report data. It is expected that students, as digital natives (Prensky, 2001), would quickly discover the technical use of the outline tool and make decisions about its appropriateness (Turner \& Katic, 2009). Students in the O-O+ condition used the outline tool only once, whereas students in the $\mathrm{O}+\mathrm{O}+$ condition used it twice and, thus, had the opportunity to appropriate the tool and experience the tool's affordances. Table 4 gives an overview of students' reported tool appropriation.

Students of both writing conditions reported that, after the outline training, they immediately understood the functioning of the outline tool. They reported a very high score concerning the technical use of the outline tool. After both writing tasks, the O-O+ condition and the $\mathrm{O}+\mathrm{O}+$ condition scored 4.64 and 4.57 respectively on a 5-point Likert scale for technical tool understanding. This is in line with the expectation that students would quickly become acquainted with the technical working of this new computer tool, since they are used to working in a computer-focused environment. In addition, both conditions reported a high score on understanding the application of the outline tool. In other words, students reported not only understanding how the outline tool could be used in theory; moreover, they understood how they could apply the tool in practice for writing an argumentative text. On both variables (i.e., technical use and application), no significant differences were found between the two conditions.

After performing both writing tasks, students from both conditions indicated whether they would use the outline tool for subsequent writing tasks and if they would recommend using the tool to a peer. Results of this questionnaire are reported in Table 5.

In the $\mathrm{O}-\mathrm{O}+$ condition, $31.6 \%$ of the students reported that they would like to use the outline tool again and in the $\mathrm{O}+\mathrm{O}+$ condition, $53.8 \%$ of the students were positive on performing future writing

Table 4

Students' appropriation of the outline tool.

\begin{tabular}{llllll}
\hline & \multicolumn{2}{l}{$\mathrm{O}-\mathrm{O}+$ condition } & & \multicolumn{2}{l}{ O+ O+ condition } \\
\cline { 2 - 3 } \cline { 5 - 6 } \cline { 5 - 6 } & $M$ & $S D$ & & $M$ & $S D$ \\
\hline Understand tool $(\max =5)$ & 4.64 & 0.79 & & 4.57 & 0.86 \\
Understand applying tool $(\max =5)$ & 4.45 & 1.06 & & 4.30 & 1.02 \\
\hline
\end{tabular}


Table 5

Students' appreciation of the outline tool.

\begin{tabular}{|c|c|c|c|c|}
\hline \multirow[t]{2}{*}{ Percentage of students who would } & \multicolumn{2}{|c|}{$\mathrm{O}-\mathrm{O}+$ condition } & \multicolumn{2}{|c|}{$\mathrm{O}+\mathrm{O}+$ condition } \\
\hline & Yes $(\%)$ & No (\%) & Yes $(\%)$ & No (\%) \\
\hline Use the outline tool again & 31.6 & 68.4 & 53.8 & 46.2 \\
\hline Recommend the outline tool & 23.5 & 76.5 & 54.7 & 48.3 \\
\hline
\end{tabular}

tasks with the outline tool. Students in both conditions were only moderately positive on using the outline tool again. However, a trend is measured which suggests that students in the $\mathrm{O}+\mathrm{O}+$ condition have a higher intention to use the outline tool again $\left(\chi^{2}(1)=2.20, p=.07\right)$. Repeated outlining may increase students' intention of future outlining.

In the $\mathrm{O}-\mathrm{O}+$ condition, $23.5 \%$ of the students indicated that they would recommend the outline tool to a peer, while in the $\mathrm{O}+\mathrm{O}+$ condition, 54.7\% reported to recommend the tool. Again, results are only moderately positive. Nevertheless, analyses show a significant difference between both conditions regarding tool recommendation $\left(\chi^{2}(1)=3.51, p=.03\right)$. Students who used the outline tool twice were significantly more positive on recommending the tool to others than students who used the tool only once. Tool practice and the experience of its benefits therefore seems important for students' tool appreciation and intention of future use (cf. Davis, 1986, 1989; Venkatesh \& Davis, 2000).

\section{Discussion}

The goal of this study was to examine the effect of repeated and single use of an electronic outline tool on students' argumentative texts. In addition, it aimed to determine the effect of electronic outlining on students' perceived mental effort while performing a writing task. Consistent with the hypothesis, marginal but beneficial effects were found for repeated tool-use on Structure Presentation. Results suggest that tool practice tends to enhance the presentation of the argumentative structure by improved use of paragraphs, connectives and anaphora (cf. Chanquoy, 1996). However, beneficial effects were only found for repeated outlining. Electronic outlining did not enhance students' Structure Presentation when it was used for the first time. Tool appropriation therefore seems an important condition to profit from electronic outlining.

Regarding the variables Total Text Structure and Hierarchical Elaboration of Arguments, no significant effects were measured both within as well as between conditions. Contrary to the hypothesis, electronic outlining had no significant effect on students' elaboration of the total text structure or their hierarchical elaboration of a complex argument. Results of this study are therefore at odds with previous studies which found that outlining benefits organizing text ideas (Glynn et al., 1982; Kellogg, 1988). This can probably be accounted for by an important difference in the context in which students performed the writing task. In most previous studies, students were given a writing assignment along with novel materials (i.e., information that needed to be read or used that was new to them). However, preceding the experimental writing tasks in this present research, students participated in a project for 5 weeks which required them to generate arguments and counterarguments in class discussions. During these discussions, text ideas would have been clustered and ordered in physical and/or mental structures. It was expected that such a decrease in task demands would help students to focus on the process of organizing text ideas into a linear structure and thus improve writing performance. Outlining would especially help them to bridge between initial mental associations and the translation of a coherent and sequentially ordered text. However, the hypothesis concerning the effect of electronic outlining on text quality were not confirmed. A possible explanation for these results could be found in Kellogg's (1990) study in which he indeed found that outlining as a planning strategy contributed to text quality. Yet, the positive effects of outlining on text quality decreased along with decreasing task demands. The benefit of outlining was entirely eliminated for a task that did not demand idea generation or organization. He therefore concluded that the benefit of outlining is greatest for tasks that require both idea generation and organization.

Even though the task of performing an argumentative text in this experiment is still complex, task demands were reduced by generating and clustering text ideas in the preceding weeks, hence the benefits of outlining were decreased. Students were familiar with the topic of their argumentative tasks and had a workable document schema in their memory which may here have eliminated the beneficial effect of outlining. Caccamise (1987) also found that writers better organize their ideas when planning a text on a familiar topic that is richly represented by schemas in memory. Using the outline tool only for text organization and not for text generation may therefore explain the inconsistency with the hypothesis and previous found results. It is however important to realize that in practical class situations, students often have to perform novel writing tasks without a preceding and extensive class debate in which arguments corresponding to the writing task are discussed. Mostly, writing tasks include both the generation and organization of ideas. In these cases, students might benefit more from outlining to create a document structure. Findings from this study may in such cases support the practice in composition instruction of stimulating students to outline during prewriting (Kellogg, 1990).

Outcomes concerning students' perceived mental effort are partly in line with the hypothesis [H3]. Significant beneficial effects were found for repeatedly using the outline tool suggesting that practice in electronic outlining decreased perceived mental effort while performing the writing task. This is in line with other studies (Shaffer et al., 2003; Sweller, Van Merriënboer, \& Paas, 1998) which found that once a particular skill is acquired, automatic processing can circumvent the limits of working memory.

However, just as for Structure Presentation, beneficial effects were only present for repeated use of the tool. Electronic outlining did not influence perceived mental effort when used for the first time. The process of tool exploration and appropriation might here have interfered with the writing process. This is a well studied and often observed effect within cognitive load theory research. Since working memory is limited, when a learner is confronted with a complex task and a new tool designed to aid in carrying out the task, the learner may at first experience extraneous load caused by the tool. Van Bruggen, Kirschner, and Jochems (2002) found this, for example, for when employing external representations intended to reduce load via cognitive off-loading.

This study shows that after a brief, technical outline instruction, students were very confident that they understood how they could use the outline tool. Furthermore, students' appreciation of the outline tool increased with increased tool practice. Students who repeatedly used the outline tool, appreciated the tool more highly. This is in line with the Technology Acceptance Model (Davis, 1986, 
1989; Davis, Bagozzi, \& Warshaw, 1989; Venkatesh \& Davis, 2000) which suggests that perceived usefulness and perceived ease of use predict a users' attitude and intention towards using a particular tool. In his study, Davis especially emphasizes the powerful effect of perceived affordances on users' actual use. This might explain in this study the difference between both conditions in their intention to recommend the tool or to use it again. Students in the $\mathrm{O}+\mathrm{O}+$ condition might have experienced the benefits of electronic outlining on Structure Presentation and perceived mental effort during the second writing task. Hence, they are more likely to use the tool for future writing.

Results of the present study show that students in both conditions perceive the outline tool as easy to use. Only a short training session and the requirement to use the tool appear to be sufficient to initiate a process of appropriating the tool for writing. Nonetheless, the outline tool was more useful for students who repeatedly used it. Benefits in writing performance (i.e., improved text structure and decreased mental effort) were most prominent for students in the $\mathrm{O}+\mathrm{O}+$ condition.

Study outcomes suggest that in order to benefit from electronic outlining, at least two requirements should be met. First, it is important to practice using the outline tool. Even though students indicate that they understand how to use the outline tool, working with such a new tool could initially cause extraneous cognitive load (i.e., load which is not directly related to the writing task, but related to learning to use the tool). It might therefore be expected that the combination of using the tool and carrying out the writing task would initially lead to increased cognitive load (i.e., increased mental effort) (Van Bruggen et al., 2002). This extraneous cognitive load decreases when students get acquainted with the outline tool. Tool practice is therefore a first important requirement to profit from electronic outlining.

Second, to profit from electronic outlining, writing tasks should include both generating and organizing text ideas. Students may not profit from the tool's structuring effects when using it for very short or routine writing tasks in which the organization and structuring of text is self-evident (Kellogg, 1988) or in which text ideas have been discussed and clustered in prior stages as was the case in this study.

In conclusion, the present research suggests that students may profit most from electronic outlining when they have mastered the tool and use it for highly demanding writing tasks that include the generation and organization of text ideas. However, further research is required to examine these assumptions in more detail. Hence, future studies should compare conditions where students did and did not generate text ideas before they are required to elaborate this in a text. Future studies should also include a third condition in which students perform both writing tasks without the outline tool. This would enable a better distinction between effects of electronic outlining and of repeatedly performing a writing task. Furthermore, in addition to the questionnaire concerning control variables, a pre-test writing task could be implemented to ensure that the performance profile of both conditions is equal.

In this study, students practiced using the outline tool during two writing tasks. It might however be relevant to examine the effect of increasing the number of practice sessions to enhance the process of automation. Moreover, the effects of electronic outlining might be examined when giving students a more elaborated didactic tool-instruction which also focuses on content and not only on technical tool-use.

The present study used self-report questionnaires to measure students' perceived mental effort. In future research more direct measures, such as secondary reaction times (Brünken, Plass, \& Leutner, 2003; Kellogg, 1988), or analyses of the students' pausingand revision behavior (Leijten, Janssen, \& Van Waes, 2010) could be used to determine expended mental effort more objectively.
This study suggests that electronic outlining, used under the right conditions, has the potential to improve students' text quality and reduce mental effort and, thus, creates perspectives for further research on optimizing the effects of electronic outlining.

\section{Role of the funding source}

The funding source had no role in the study design; in the collection, analysis and interpretation of data; in the writing of the report; and in the decision to submit the article for publication.

\section{Acknowledgement}

This research project was generously funded by the Kennisnet Foundation, the knowledge centre for information and communication technologies and education in the Netherlands.

\section{References}

Bereiter, C., \& Scardamalia, M. (1987). The psychology of written composition. Hillsdale, NJ: Lawrence Erlbaum Associates.

Braaksma, M. A. H. (2002). Observational learning in argumentative writing (Unpublished doctoral dissertation). University of Amsterdam.

Braaksma, M. A. H., Rijlaarsdam, G., \& Van den Bergh, H. (2009, August). Hypertext writing: Effects on writing processes and writing products. Paper presented at the 12th conference of the European Association for Research on Learning and Instruction (EARLI), Budapest, Hungary.

Brünken, R., Plass, J. L., \& Leutner, D. (2003). Direct measurement of cognitive load in multimedia learning. Educational Psychologist, 38, 53-61.

Caccamise, D. J. (1987). Idea generation in writing. In A. Matsuhasi (Ed.), Writing in real time: Modeling production processes (pp. 224-253). Norwood, NJ: Ablex

Chanquoy, L. (1996, October). Connectives and argumentative text: A developmental study. Paper presented at the First International Workshop on Argumentative Text Processing, Barcelona, Spain.

Coirier, P., Andriessen, J. E. B., \& Chanquoy, L. (1999). From planning to translating: The specificity of argumentative writing. In P. Coirier \& J. E. B. Andriessen (Eds.), Foundations of argumentative text processing (pp. 1-29). Amsterdam, the Netherlands: Amsterdam University Press.

Coirier, P., Favart, M., \& Chanquoy, L. (2002). Ordering and structuring ideas in text: From conceptual organization to linguistic formulation. European Journal of Education, 17(2), 157-175.

Davis, F. D. (1986). A technology acceptance model for empirically testing new end-user information systems: Theory and results (Unpublished doctoral dissertation.) MIT Sloan School of Management.

Davis, F. D. (1989). Perceived usefulness, perceived ease of use, and user acceptance of information technology. MIS Quarterly, 13, 319-339.

Davis, F. D., Bagozzi, R. P., \& Warshaw, P. R. (1989). User acceptance of computer technology: A comparison of two theoretical models. Management Science, 35 982-1003.

De Smet, M. J. R., Broekkamp, H., Brand-Gruwel, S., \& Kirschner, P. A. (2011). Effects of electronic outlining on students' argumentative writing performance. Journal of Computer Assisted Learning, 27(6), 557-574. doi: 0.1111/j.13652729.2011.00418.x.

Deacon, A., Jaftha, J., \& Horwitz, D. (2004). Customising Microsoft Office to develop a tutorial learning environment. British Journal of Educational Technology, 35, 223-234.

DeVellis, R. R. (1991). Scale development: Theory and applications. Thousand Oaks, CA: Sage.

Duijnhouwer, H. (2010). Feedback effects on students' writing motivation, process, and performance (Unpublished doctoral dissertation). The Netherlands: University of Utrecht

Elbow, P. (1998). Writing with power: Techniques for mastering the writing process. Oxford, NY: Oxford University Press.

Englert, C. S., Zhao, Y., Dunsmore, K., Collings, N. Y., \& Wolbers, K. (2007). Scaffolding the writing of students with disabilities through procedural facilitation: Using an internet-based technology to improve performance. Learning Disability Quarterly, 30(1), 9-29.

Erkens, G., Jaspers, J. G. M., Prangsma, M. E., \& Kanselaar, G. (2005). Coordination processes in computer supported collaborative writing. Computers in Human Behavior, 21, 463-486.

Erkens, G., Kanselaar, G., Prangsma, M., \& Jaspers, J. (2002). Using tools and resources in computer supported collaborative writing. In G. Stahl (Ed.), Computer support for collaborative learning: Foundations for a CSCL community (pp. 389-399). Hillsdale, NJ: Lawrence Erlbaum Associates.

Faigley, L., \& Witte, S. (1981). Analyzing revision. College Composition and Communication, 32(4), 400-414.

Flower, L. S., \& Hayes, J. R. (1981). A cognitive process: Theory of writing. College Composition and Communication, 32(4), 365-387.

Flower, L. S., \& Hayes, J. R. (1980). The dynamics of composing: Making plans and juggling constraints. In L. W. Gregg \& E. R. Steinberg (Eds.), Cognitive processes in 
writing: An interdisciplinary approach. Hillsdale, NJ: Lawrence Erlbaum Associates.

Galbraith, D., Ford, S., Walker, G., \& Ford, J. (2005). The contribution of different components of working memory to knowledge transformation during writing. Educational Studies in Language and Literature, 5, 113-145.

Glynn, S. M., Britton, B. K., Muth, K. D., \& Dogan, N. (1982). Writing and revising persuasive documents: Cognitive demands. Journal of Educational Psychology, 74, 557-567.

Gopher, D., \& Braune, R. (1984). On the psychophysics of workload: Why bother with subjective measures? Human Factors, 26, 519-532.

Hayes, J. R. (2006). New directions in writing theory. In C. A. MacArthur, S. Graham, \& J. Fitzgerald (Eds.), Handbook of writing research (pp. 28-40). New York, NY: The Guilford Press.

Hayes, J. R., \& Nash, J. (1996). On the nature of planning in writing. In C. Levy \& S. Ransdell (Eds.), The science of writing (pp. 29-55). Mahwah, NJ: Lawrence Erlbaum Associates.

Kellogg, R. T. (1987). Writing performance: Effects of cognitive strategies. Written Communication, 4, 269-298.

Kellogg, R. T. (1988). Attentional overload: Effects of rough draft and outline strategies. Journal of Experimental Psychology: Learning, Memory and Cognition, $14,355-365$.

Kellogg, R. T. (1990). Effectiveness of prewriting strategies as a function of task demands. American Journal of Psychology, 103, 327-342.

Kellogg, R. T. (1994). The psychology of writing. New York, NY: University Press

Kellogg, R. T. (2008). Training writing skills: A cognitive developmental perspective. Journal of Writing Research, 1(1), 1-26.

Kellogg, R. T. (1996). A model of working memory in writing. In C. M. Levy \& S. Ransdell (Eds.), The science of writing: Theories, methods, individual differences, and applications. Mahwah, NJ: Erlbaum, pp. 75-71.

Kellogg, R. T., \& Whiteford, A. P. (2009). Training advanced writing skills: The case for deliberate practice. Educational Psychologist, 44(4), 250-266.

Kieft, M. (2006). The effects of adapting writing instruction to students' writing strategies (Unpublished doctoral dissertation). Amsterdam, The Netherlands: University of Amsterdam, Graduate School of Teaching and Learning.

Kieft, M., Rijlaarsdam, G., Galbraith, D., \& Van den Berg, H. (2007). The effects of adapting a writing course to students' writing strategies. British Journal of Educational Psychology, 77, 565-578.

Kirschner, P. A. (2002). Cognitive load theory: Implications of cognitive load theory on the design of learning. Learning and Instruction, 12(1), 1-10.

Kozma, R. (1991). The impact of computer-based tools and embedded prompts on writing processes and products of novice and advanced college writers. Cognition and Instruction, 8(1), 1-27.

Leijten, M. (2007). Writing and speech recognition. Observing error correction strategies of professional writers (Unpublished doctoral dissertation). LOT, Utrecht, the Netherlands.
Leijten, M., Janssen, D., \& Van Waes, L. (2010). Error correction strategies of professional speech recognition users: Three profiles. Computers in Human Behavior, 26, 964-975.

McCutchen, D. (1987). Children's discourse skills: Form and modality requirements of schooled writing. Discourse Processes, 10(3), 267-286.

Paas, F. (1992). Training strategies for attaining transfer of problem-solving skill in statistics: A cognitive-load approach. Journal of Educational Psychology, 84, 429-434.

Piolat, A., \& Roussey, J.-Y. (1996). Students' drafting strategies and text quality. Learning and Instruction, 6(2), 111-129.

Prensky, M. (2001). Digital Natives, digital immigrants, part II: Do they really think differently? On the Horizon, 9, 1-6.

Price, J. (1997). Electronic outlining as a tool for making writing visible. Computers and Composition, 14, 409-427.

Schilperoord, J. (1996). It's about time. Temporal aspects of cognitive processes in text production. Amsterdam, Atlanta: GA.

Shaffer, D., Doube, W., \& Tuovinen, J. (2003, April). Applying cognitive load theory to Computer Science Education. Paper presented at the 15th workshop of the psychology of programming interest group, Keele, UK. <http://www.ppig.org/ papers/15th-shaffer.pdf>.

Sweller, J., Van Merriënboer, J. J. G., \& Paas, F. G. W. C. (1998). Cognitive architecture and instructional design. Educational Psychology Review, 10(3), 251-296.

Torrance, M., Thomas, G. V., \& Robinson, E. J. (2000). Individual differences in undergraduate essay-writing strategies: A longitudinal study. Higher Education, $39,181-200$.

Turner, K. H., \& Katic, E. K. (2009). The influence of technological literacy on students' writing. Journal of Educational Computing Research, 41, 253-270.

U.S. Department of Education (2003). Institute of Education Sciences, National Center for Education Statistics. The Nation's report card: Writing 2002 (NCES 2003-529). 2003529.pdf>.

Van Bruggen, J. M., Kirschner, P. A., \& Jochems, W. (2002). External representation of argumentation in CSCL and the management of cognitive load. Learning and Instruction, 12, 121-138.

Van Weijen, D. (2007). Writing processes, text quality, and task effects. Empirical studies in first and second language writing (Unpublished doctoral dissertation), Utrecht, the Netherlands: LOT.

Venkatesh, V., \& Davis, F. D. (2000). A theoretical extension of the technology acceptance model: Four longitudinal field studies. Management Science, 46(2), 186-204.

Walvoord, B. E., Anderson, V. J., Breihan, J. R., McCarthy, L. P., Robison, S. M., \& Sherman, A. K. (1995). Functions of outlining among college students in four disciplines. Research in the Teaching of English, 29, 390-421. 